\title{
Evaluation of Susceptibility of Asphalt Binders to Rutting through MSCR Test
}

\author{
Rong Chang $\mathbb{D}^{1,2}$ Aimin Sha $\mathbb{D}^{1,},{ }^{1}$ Pinxue Zhao, ${ }^{1}$ Songchang Huang, ${ }^{2}$ and Cong $\mathrm{Qi}^{3}$ \\ ${ }^{1}$ Key Laboratory for Special Area Highway Engineering of Ministry of Education, Chang'an University, Xi'an 710064, China \\ ${ }^{2}$ Resrarch Institute of Highway Ministry of Transport, Beijing 100088, China \\ ${ }^{3}$ Shandong Chambroad Petrochemicals Co. Ltd., Binzhou, Shandong 256500, China
}

Correspondence should be addressed to Aimin Sha; ams@chd.edu.cn

Received 17 November 2021; Accepted 13 December 2021; Published 30 December 2021

Academic Editor: Meng Guo

Copyright (C) 2021 Rong Chang et al. This is an open access article distributed under the Creative Commons Attribution License, which permits unrestricted use, distribution, and reproduction in any medium, provided the original work is properly cited.

Using modified asphalt binder is one of the most effective methods to solve the rutting problem of asphalt pavement, but the traditional $G^{*} / \sin \delta$ parameter is not enough to characterize the rutting resistance of modified asphalt in field use. In order to accurately evaluate the high temperature performance of asphalt and establish the relationship between the rutting resistance of binder and mixture, two kinds of matrix asphalt and three kinds of modified asphalt were selected for DSR and MSCR tests. $G^{*} / \sin \delta$, nonrecoverable creep compliance $J_{\mathrm{nr}}$, recovery rate $R$, and other parameters were used to characterize the permanent deformation resistance of the binder, and the correlation between these parameters and the results of rutting test was analyzed. The results show that $J_{\mathrm{nr} 3.2}$ can accurately characterize the permanent deformation resistance of asphalt, while the stress sensitivity index $J_{\text {nrdiff }}$ is not applicable to all types of modified asphalt. In contrast, $J_{\text {nrslope }}$ can better reflect the stress sensitivity of asphalt, and $J_{\text {nrslope }}$ is significantly correlated with the results of rutting test.

\section{Introduction}

Rutting is one of the main forms of pavement damage. For semirigid base pavement, the cumulative plastic deformation under repeated load is the main reason for rutting of asphalt mixture $[1,2]$. The cohesive force of asphalt and the extrusion force between aggregate constitute the rutting resistance of asphalt mixture, of which the contribution of cohesive force of asphalt accounts for about 40\% [3-5]. Compared with the rutting test of asphalt mixture, it is much easier to predict the rutting performance of asphalt mixture by testing the permanent deformation resistance of asphalt binder. However, the difficulty lies in finding the most representative asphalt parameters to characterize the rutting resistance of asphalt mixture.

Penetration, softening point, and viscosity are commonly used to evaluate the rutting resistance of asphalt binders. However, relevant research shows that these indicators have no good correlation with the field performance of asphalt pavement [6]. The asphalt performance grading system of SUPERPAVE measures the rheological properties of asphalt binders at specific temperature and loading frequency through dynamic shear rheometer (DSR) test, and the rutting factor $G^{*} / \sin \delta$ derived based on dissipative energy theory is used as the high temperature performance evaluation index for original asphalt and residual asphalt aged by rolling thin film oven (RTFO) test [7]. However, relevant studies show that compared with evaluating modified asphalt performance, $G^{*} / \sin \delta$ is more accurate in evaluating the performance of matrix asphalt with linear viscoelasticity. Moreover, the dynamic sinusoidal alternating load applied continuously in DSR test does not reflect the better delayed elastic recovery ability of modified asphalt, and the study of NCHRP9-10 also proves this point. The correlation between the permanent deformation rate measured by repeated shear test (constant height) (RSCH) and $G^{*} / \sin \delta$ is not significant [8-10].

With the increase of traffic load and environmental temperature, more and more modified asphalts are used to solve the problem of pavement rutting. In order to 
characterize the rutting resistance of asphalt more accurately, new parameters such as Sheony parameter, zero shear viscosity (ZSV), and unrecoverable creep compliance are proposed. Among them, the unrecoverable creep compliance obtained by multiple stress creep recovery (MSCR) test is considered to be able to evaluate the rutting resistance potential of asphalt [11-14].

MSCR test is developed from repeated creep and recovery (RCR) test. It evaluates the high temperature rutting resistance of asphalt binder with unrecoverable creep compliance $J_{\text {nr }}$ and recovery rate $R$ and takes $J_{\text {nrdiff }}$ as the stress sensitivity index of asphalt binder. AASHTO MP 19-10 proposed an asphalt classification method based on MSCR test [15]. The unrecoverable creep compliance $J_{\text {nr3.2 }}$ was used to classify the performance grade of asphalt at service temperature and then judge which of the four traffic grades (S (standard), H (heavy), V (very heavy), E (extreme)) can the asphalt serve for. At the same time, the stress sensitivity index $J_{\text {nrdiff }}$ is required to be no more than $75 \%$. MSCR test leaves a recovery time for the viscoelastic strain generated by the creep part of asphalt after unloading, thus providing a method to separate the permanent strain from the total strain, which is better correlated with the field rutting [16]. Compared with DSR test, the parameters obtained by MSCR test can better evaluate the rutting resistance of modified asphalt $[17,18]$. The unrecoverable creep compliance measured at $0.1 \mathrm{kPa}$ and $3.2 \mathrm{kPa}$ shows excellent repeatability and reproducibility [19].

This study aims to evaluate the high temperature permanent deformation resistance of asphalt binder and study the relationship between asphalt binder and rutting resistance of asphalt mixture. In this study, MSCR and DSR were used to evaluate the high temperature performance of two kinds of matrix asphalt and three kinds of modified asphalt before and after aging. At the same time, the asphalt mixture with the same mineral gradation was prepared for rutting test, and the test results of asphalt binder and mixture were compared.

\section{Materials and Asphalt Mixture Design}

2.1. Binders. In this study, five kinds of asphalt were selected, including Shandong Jingbo AH-70, Jiangxi Sinopec AH-90, Jiangsu Sinopec SBS I-C, Jiangsu Sinopec SBS I-D, and Gansu high viscosity asphalt HVG. Among them, AH-70 and AH-90 were matrix asphalt, and SBS I-C, SBS I-D, and HVG were modified asphalt. According to Standard Test Methods of Asphalt and Asphalt Mixtures for Highway Engineering (JTG E20-2011) T0610 method, five kinds of asphalt were heated by rotating thin film oven for $75 \mathrm{~min}$ at $163 \pm 1^{\circ} \mathrm{C}$ to simulate the short-term aging state of asphalt [20]. The conventional properties of unaged and aged asphalt are, respectively, given in Tables 1 and 2 .

2.2. Aggregates. Both coarse aggregate and fine aggregate are limestone, and the filler is limestone powder. Aggregate and filler are from the same origin, and their properties (shown in Table 3) meet the requirements of Technical Specifications for Construction of Highway Asphalt Pavements (JTG F402004) [21].

2.3. Asphalt Mixture Design. In this paper, the gradation types of asphalt mixtures prepared with five different asphalts are all continuous gradation AC-13, and the gradation curves are shown in Figure 1.

The asphalt mixture in this study is designed by Marshall test. The optimum amount of asphalt mixture prepared by five different asphalts is determined by Marshall test to control the porosity of rutting test made by each asphalt. The Marshall test results are shown in Table 4.

\section{Experimental Program}

3.1. Dynamic Shear Rheometer (DSR) Test. The dynamic shear rheometer (DSR) test was performed in accordance with the AASHTO T315 standard test method [7]. Malvern dynamic shear rheometer (Figure 2) was used as the test instrument. The strain control mode is adopted in the test. The control strain value of the unaged asphalt is $12 \%$, and the control strain value of the aged asphalt is $10 \%$. The shear rate of the test is $10 \mathrm{rad} / \mathrm{s}(1.592 \mathrm{~Hz})$, and the test temperature is $64^{\circ} \mathrm{C} \sim 88^{\circ} \mathrm{C}$. The binder sample was placed between two parallel plates $(25.0 \mathrm{~mm}$ diameter, $1.0 \mathrm{~mm}$ plate spacing) of the dynamic shear rheometer, and the test can start after 15 minutes of constant temperature.

3.2. Multiple Stress Creep Recovery (MSCR) Test. The MSCR test in this paper is carried out according to the AASHTO T350 standard test method [22]. The test instrument is still Kinexus Ultra + intelligent rotary rheometer from Malvern Company, and the test temperature is also $64^{\circ} \mathrm{C} \sim 88^{\circ} \mathrm{C}$. After 20 cycles of loading and recovery at a stress level of $0.1 \mathrm{kPa}$, the aged asphalt sample was immediately subjected to 10 cycles of loading and recovery at a stress level of $3.2 \mathrm{kPa}$, without any interval between the two stages. Loading and looping is usually done after $1 \mathrm{~s}$ of loading, and the sample is removed to allow it to resume for $9 \mathrm{~s}$.

The nonrecoverable creep compliance $J_{\mathrm{nr}}$ (equation (1)) and recovery rate $R$ (equation (2)) reflecting the rutting resistance potential of asphalt can be obtained through MSCR test. Considering the variability of measured values, $J_{\text {nr0.1 }}$ and $R_{0.1}$ of asphalt samples under $0.1 \mathrm{kPa}$ stress cycle and $J_{\mathrm{nr} 3.2}$ and $R_{3.2}$ of asphalt samples under $3.2 \mathrm{kPa}$ stress cycle are calculated according to equation (3) (6).

$$
\begin{aligned}
R & =\frac{\varepsilon_{p}-\varepsilon_{u}}{\varepsilon_{p}} \times 100 \%, \\
J_{n r} & =\frac{\varepsilon_{u}}{\sigma},
\end{aligned}
$$

where $\varepsilon_{p}$ is the peak strain, $\varepsilon_{u}$ is the residual strain that cannot be restored at the end of the recovery stage, and $\sigma$ is the corresponding stress level imposed by the two stages. 
TABle 1: Properties of unaged binders.

\begin{tabular}{|c|c|c|c|c|c|c|c|}
\hline Items & Unit & AH-70 & AH-90 & SBS I-C & SBS I-D & HVG & Experiment method \\
\hline Penetration $\left(15^{\circ} \mathrm{C}\right)$ & $\mathrm{dmm}$ & 33 & 28 & 29 & 22 & 29 & T0604 \\
\hline Penetration $\left(25^{\circ} \mathrm{C}\right)$ & $\mathrm{dmm}$ & 77 & 85 & 78 & 60 & 72 & T0604 \\
\hline Penetration $\left(30^{\circ} \mathrm{C}\right)$ & $\mathrm{dmm}$ & 123 & 139 & 114 & 87 & 97 & T0604 \\
\hline Penetration index & $\mathrm{n} / \mathrm{a}$ & 0 & -1 & 0 & 0 & 1 & T0604 \\
\hline Softening point & ${ }^{\circ} \mathrm{C}$ & 54 & 53 & 92 & 95 & 87 & T0606 \\
\hline Viscosity $\left(60^{\circ} \mathrm{C}\right)$ & $\mathrm{Pa} \cdot \mathrm{s}$ & 287 & 208 & 28728 & 52243 & 58061 & T0620 \\
\hline
\end{tabular}

TAble 2: Properties of aged binders.

\begin{tabular}{|c|c|c|c|c|c|c|c|}
\hline Items & Unit & AH-70 & AH-90 & SBS I-C & SBS I-D & HVG & Experiment method \\
\hline Penetration $\left(15^{\circ} \mathrm{C}\right)$ & $\mathrm{dmm}$ & 18 & 19 & 21 & 21 & 29 & T0604 \\
\hline Penetration $\left(25^{\circ} \mathrm{C}\right)$ & $\mathrm{dmm}$ & 41 & 48 & 49 & 43 & 53 & T0604 \\
\hline Penetration $\left(30^{\circ} \mathrm{C}\right)$ & $\mathrm{dmm}$ & 60 & 75 & 79 & 61 & 75 & T0604 \\
\hline Penetration index & $\mathrm{n} / \mathrm{a}$ & 1 & 0 & 0 & 2 & 3 & T0604 \\
\hline Softening point & ${ }^{\circ} \mathrm{C}$ & 60 & 58 & 69 & 70 & 85 & T0606 \\
\hline Viscosity $\left(60^{\circ} \mathrm{C}\right)$ & $\mathrm{Pa} \cdot \mathrm{s}$ & 809 & 593 & 36543 & 58061 & 96442 & T0620 \\
\hline
\end{tabular}

TABle 3: Properties of aggregates.

\begin{tabular}{lccc}
\hline Items & Unit & Experimental value & Normative value \\
\hline Apparent density & - & 2.689 & $\geq 2.5$ \\
Water absorption & $\%$ & 0.64 & - \\
Angularity & $s$ & 41.7 & $\geq 30$ \\
Sediment concentration & $\%$ & 64 & $\geq 60$ \\
\hline
\end{tabular}

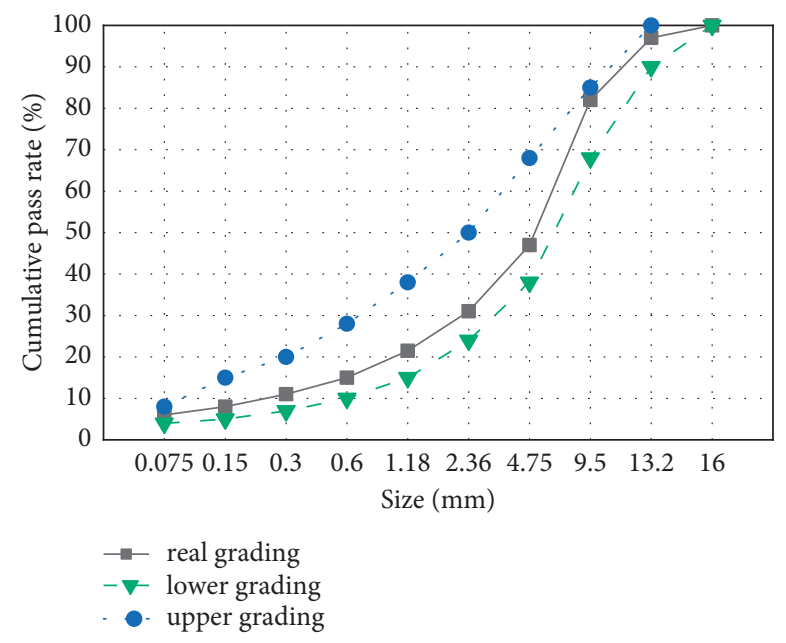

FIgURE 1: Grading curve.

TABLe 4: Result of Marshall test.

\begin{tabular}{|c|c|c|c|c|c|}
\hline Type of binders & Optimum asphalt content (\%) & Apparent density $\left(\mathrm{g} / \mathrm{cm}^{3}\right)$ & VV (\%) & VMA (\%) & VFA (\%) \\
\hline AH-70 & 4.6 & 2.507 & 4.60 & 14.64 & 70.56 \\
\hline AH-90 & 4.6 & 2.510 & 4.69 & 14.53 & 69.83 \\
\hline SBS I-C & 4.9 & 2.486 & 4.43 & 15.27 & 73.13 \\
\hline SBS I-D & 4.9 & 2.492 & 4.46 & 15.10 & 72.62 \\
\hline HVG & 5.1 & 2.481 & 4.38 & 15.42 & 73.44 \\
\hline
\end{tabular}




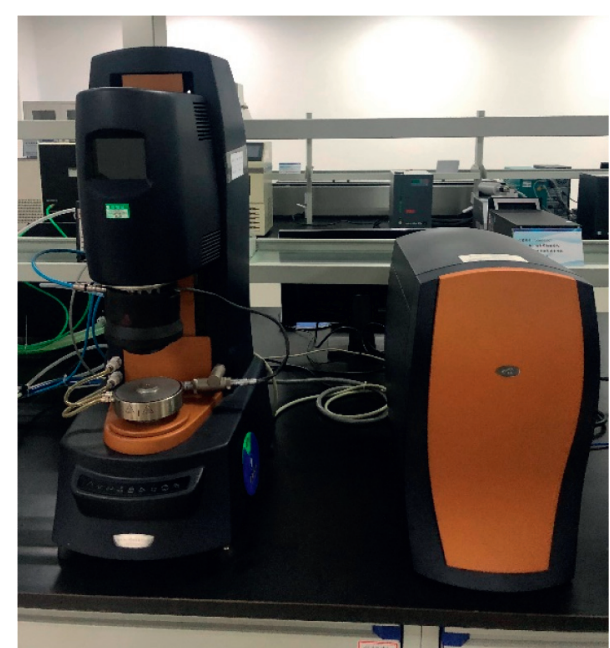

FIgURE 2: Kinexus ultra + rotational rheometer.

$$
\begin{array}{cc}
J_{n r 0.1}=\frac{\operatorname{SUM}\left[J_{n r}(0.1, N)\right]}{10}, & (N=11 \sim 20), \\
J_{n r 3.2}=\frac{\operatorname{SUM}\left[J_{n r}(3.2, N)\right]}{10}, & (N=1 \sim 10), \\
R_{0.1}=\frac{\operatorname{SUM}\left[\varepsilon_{r}(0.1, N)\right]}{10}, & (N=11 \sim 20), \\
R_{3.2}=\frac{\operatorname{SUM}\left[\varepsilon_{r}(0.1, N)\right]}{10}, & (N=1 \sim 10) .
\end{array}
$$

$J_{\text {nr0.1 }}$ and $R_{0.1}$ are the mean values of $J_{\mathrm{nr}}$ and $R \%$ measured in the ten $0.1 \mathrm{kPa}$ stress cycles after preshearing of the first ten $0.1 \mathrm{kPa}$ stress cycles, while $J_{\mathrm{nr} 3.2}$ and $R_{3.2}$ are the mean values of $J_{\mathrm{nr}}$ and R\% measured in the ten $3.2 \mathrm{kPa}$ stress cycles of the asphalt samples.

$J_{\text {nrdiff }}$ (equation (7)) is used as an evaluation index of stress sensitivity of asphalt binder to ensure that asphalt performance will not be degraded due to excessive temperature or excessive load in actual use, and its maximum limit is 75\%[23]. However, some researchers have found that the $J_{\text {nrdiff }}$ of some modified asphalts with strong resilience is usually greater than $75 \%$ due to too small $J_{\mathrm{nr} 0.1}$ or too large $J_{\mathrm{nr} 3.2}$, and there is no significant correlation between $J_{\text {nrdiff }}$ and rutting test results [24, 25]. Therefore, Stempihar proposed a new parameter $J_{\text {nrslope }}$ (equation (8)) as a new stress sensitivity evaluation index. $J_{\text {nrslope }}$ is the slope (percentage) of the $J_{\mathrm{nr}}$-stress relationship between 0.1 and $3.2 \mathrm{kPa}$ stress levels, which can better describe the relationship between the nonrecoverable creep compliance variable and the rut variable [26].

$$
\begin{gathered}
J_{n r \text { diff }}=\frac{J_{n r 3.2}-J_{n r 0.1}}{J_{n r 0.1}} \times 100 \%, \\
J_{\text {nr slope }}=\frac{J_{n r 3.2}-J_{n r 0.1}}{3.1} \times 100 \% .
\end{gathered}
$$

3.3. Wheel Rut Test. The rutting test method adopted in this paper is carried out in accordance with the method specified in the Standard Test Methods of Asphalt and Asphalt Mixtures for Highway Engineering (JTG E20-2011) [20]. The plate specimen of asphalt mixture was formed by rolling molding method (T0703-2011) with the size of $300 \mathrm{~mm} \times 300 \mathrm{~mm} \times 50 \mathrm{~mm}$. The test temperature was $60^{\circ} \mathrm{C}$, and the wheel pressure was $0.7 \mathrm{MPa}$. The test wheel walked along the same track on the specimen surface repeatedly at the frequency of $42 \pm 1 \mathrm{time} / \mathrm{min}$, and the depth of the rut formed on the specimen surface under the repeated action of the test wheel was tested to calculate the number of walks required for each $1 \mathrm{~mm}$ of rutting deformation, namely, the dynamic stability (DS). The rutting resistance of asphalt mixture is evaluated by the dynamic stability. The calculation formula of dynamic stability is

$$
D S=\frac{\left(t_{2}-t_{1}\right) \times N}{d_{2}-d_{1}} \times c_{1} \times c_{2},
$$

where DS is the dynamic stability; $t_{1}, t_{2}$ are the test time of $45 \mathrm{~min}$ and $60 \mathrm{~min}$; and $d_{1}, d_{2}$ are the vertical deformation depth corresponding to $t_{1}, t_{2} ; c_{1}, c_{2}$ are the type of testing machine and the correction coefficient of specimen, both of which are 1.0.

\section{Results and Discussion}

4.1. Temperature Sweep Test. The complex modulus $\mathrm{G}^{*}$ and phase angle $\delta$ were obtained by DSR test, and then the rutting factor $G^{*} / \sin \delta$ was calculated to evaluate the rutting potential of asphalt. The calculated results are shown in Figure 3. The rutting factor $G^{*} / \sin \delta$ decreases with the increase of temperature, indicating that the higher the temperature, the worse the antirutting ability of asphalt. According to Superpave, the original asphalt $G^{*} / \sin \delta \geq 1.0 \mathrm{kPa}$ and aged asphalt $G^{*} / \sin \delta \geq 2.2 \mathrm{kPa}$ can be considered to have good resistance to permanent deformation. In this study, $G^{*} / \sin \delta$ of the unaged base asphalt decreases to less than $1 \mathrm{kPa}$ before $70^{\circ} \mathrm{C}$. That is to say, the base asphalt at $70^{\circ} \mathrm{C}$ high temperature resistance to permanent deformation ability can no longer meet the requirements of pavement, while the modified asphalt still has good resistance to permanent deformation at $76^{\circ} \mathrm{C} \sim 82^{\circ} \mathrm{C}$. After short-term aging, the resistance to permanent deformation of both modified and unmodified asphalt decreases. However, in general, $G^{*} / \sin \delta$ of modified asphalt is greater than that of matrix asphalt, indicating that the rutting resistance of modified asphalt is better than that of matrix asphalt.

4.2. MSCR Test. Figure 4 shows that the $J_{\text {nr }}$ value of asphalt increases exponentially with the increase of temperature $T$, which indicates that, under high temperature conditions, the high temperature stability of asphalt will weaken with the increase of temperature. The overall trend of $R$ value of asphalt decreases with the increase of temperature $T$, indicating that, with the increase of temperature, the elastic recovery of asphalt decreases and the property of asphalt is 

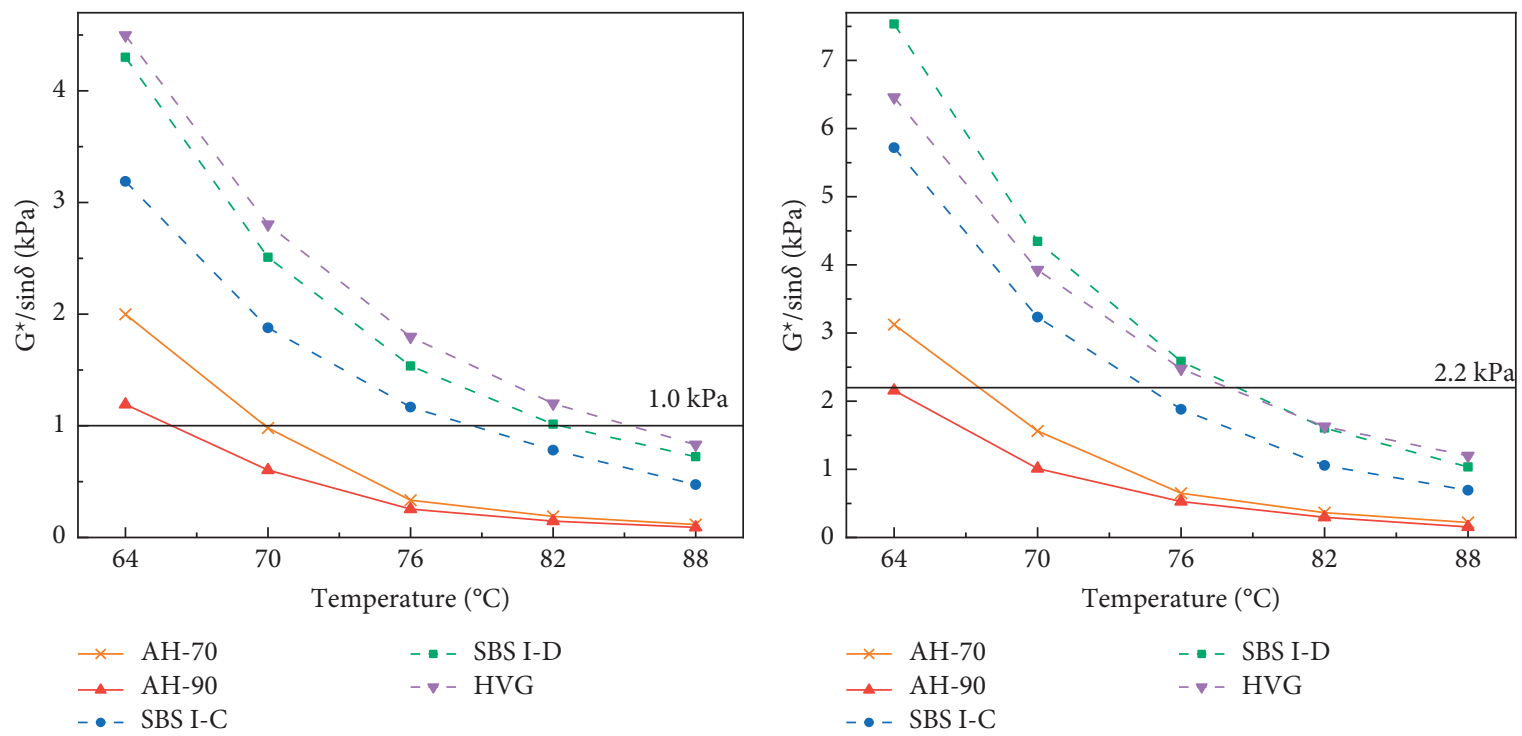

(a)

(b)

Figure 3: $G^{*} / \sin \delta$ at five different testing temperatures: (a) unaged and (b) aged.
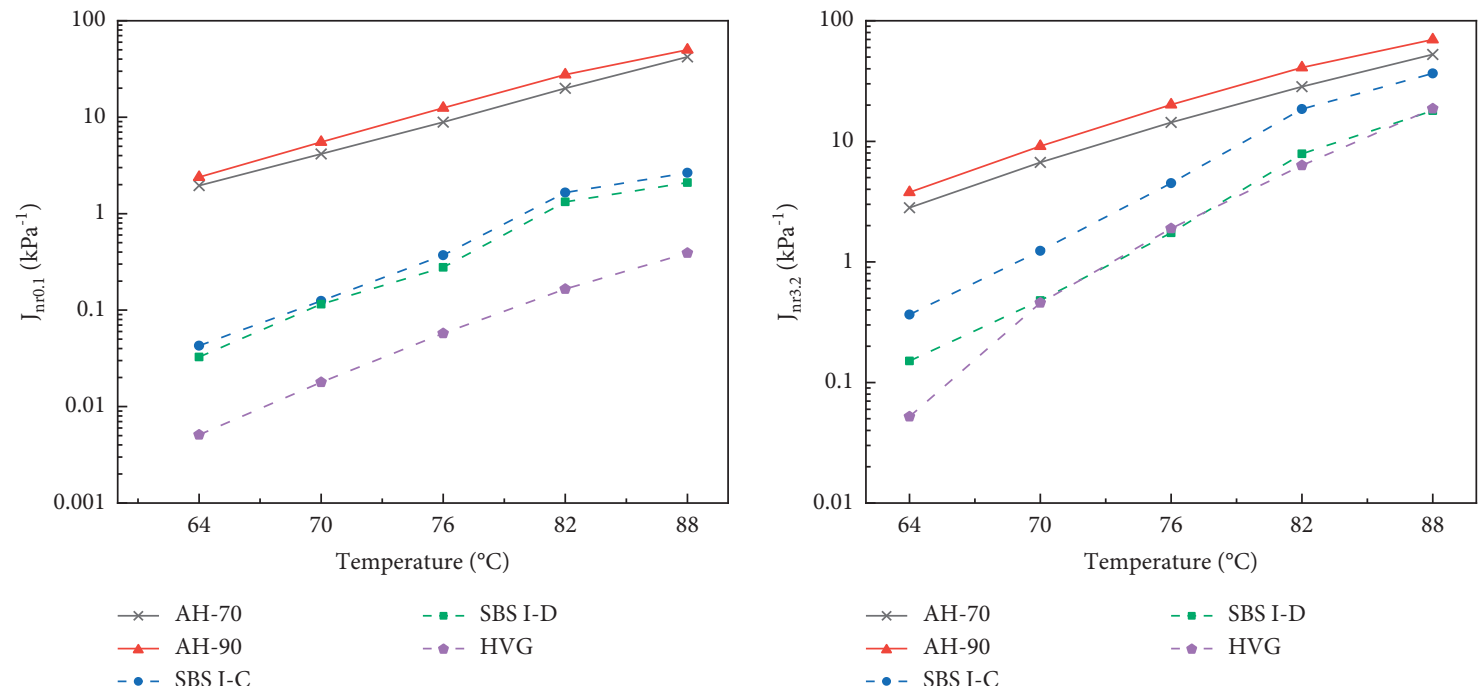

(a)
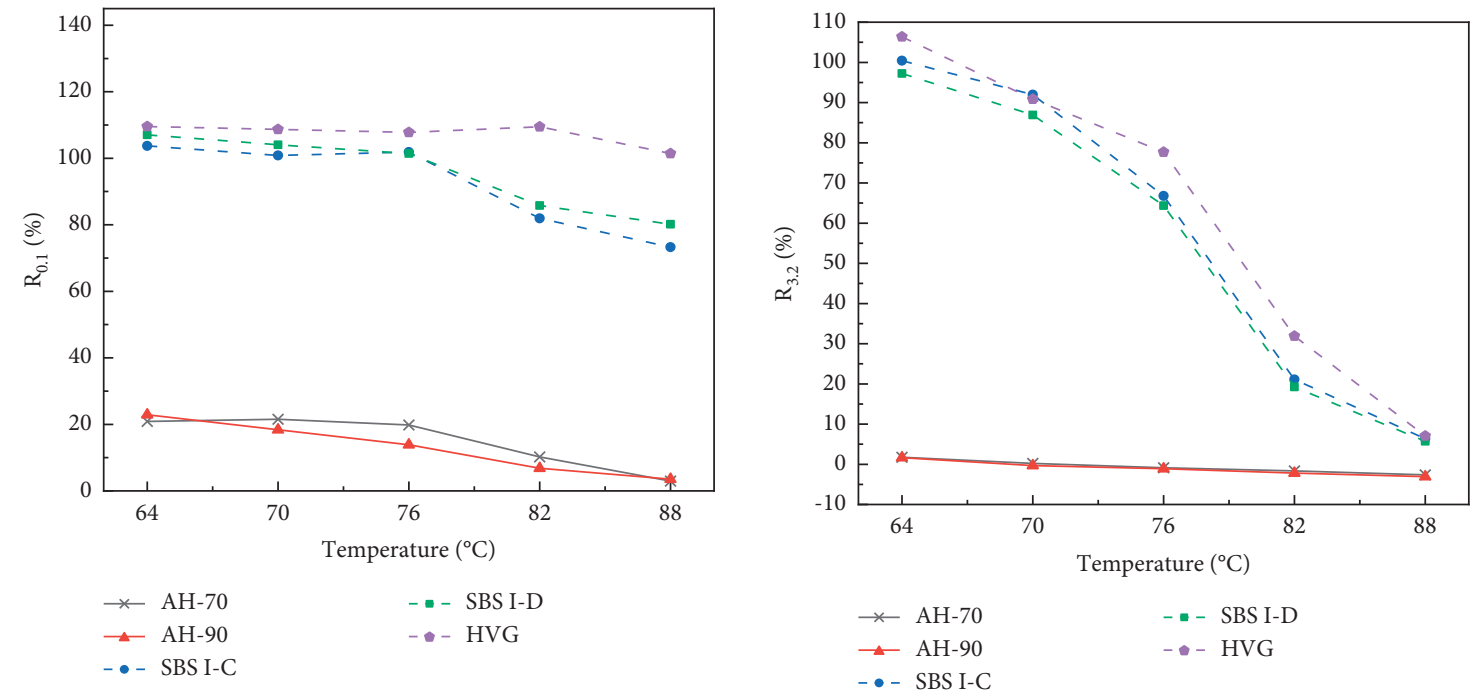

(c)

(d)

Figure 4: Continued. 


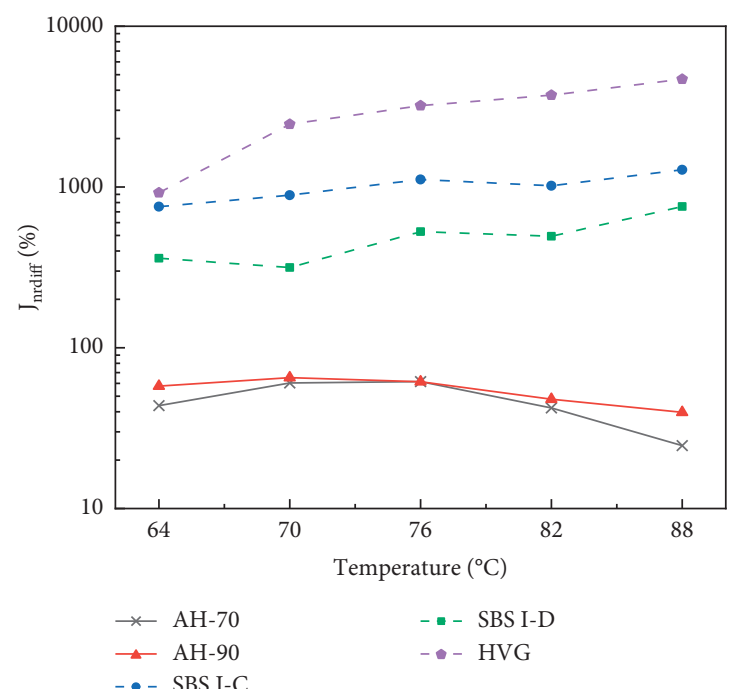

(e)

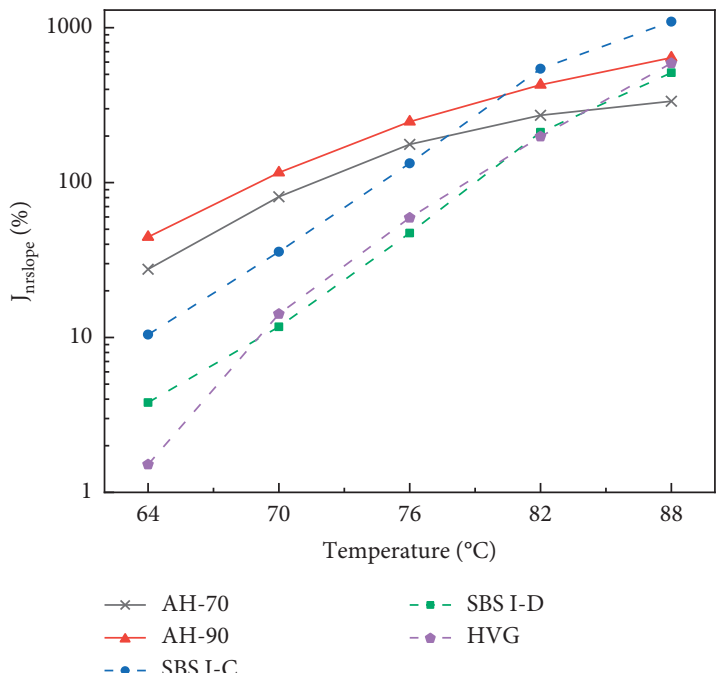

(f)

FIGURE 4: MSCR results at five different temperatures: (a) $J_{\text {nr0.1 }}$ (b) $J_{\text {nr3.2. }}$ (c) $R_{0.1}$ (d) $R_{3.2}$. (e) $J_{\text {nrdiff }}$ (f) $J_{\text {nrslope }}$.

closer to the viscous materials. In addition, $R_{0.1}$ of all asphalts is greater than $R_{3.2}$, indicating that the deformation of asphalt under high stress horizontal shear is more difficult to recover than that under low stress horizontal shear, which is also illustrated by the $J_{\mathrm{nr}}$ results.

The $R_{0.1}$ of base and modified asphalt hardly changes in a certain temperature range and begins to decline rapidly after exceeding a certain temperature threshold. It shows that the structure of asphalt can be kept stable and the viscoelastic properties do not change in a certain temperature range at a lower temperature and stress level. However, when the temperature exceeds a certain critical temperature, the elasticity ratio decreases and the asphalt structure is damaged. It can be observed from Figure 4 that $R_{3.2}$ of $\mathrm{AH}-70$ and $\mathrm{AH}-90$ asphalt is less than 0 after $76^{\circ} \mathrm{C}$ and $70^{\circ} \mathrm{C}$, respectively. Similar reports have been reported in other studies $[27,28]$. The reason for this may be that the matrix asphalt has a weak ability to resist high temperature deformation and generates third-order creep under the action of high temperature and high stress, which can still flow when the stress is 0 . Another possible reason is that there is a delay in unloading the DSR, and part of the minor stress still acts on the asphalt after unloading, resulting in the deformation of the substrate asphalt which is too soft at high temperature. $R_{3.2}$ of modified asphalt decreased rapidly in the temperature range of $76^{\circ} \mathrm{C}-82^{\circ} \mathrm{C}$, and the corresponding $J_{\mathrm{nr} 3.2}$ also began to rise rapidly, indicating that the modified asphalt could still maintain structural stability to a certain extent at low temperature, while maintaining good rutting resistance. However, once the temperature exceeded the critical value, the viscoelastic properties of modified asphalt changed, the elastic ratio decreased rapidly, and the rutting resistance also decreased rapidly.

If $J_{\text {nrdiff }}$ is used as an indicator of asphalt stress sensitivity, HVG is considered to have the highest stress sensitivity, while $\mathrm{AH}-70$ is considered to have the lowest stress sensitivity, which contradicts the results of $J_{\mathrm{nr}}$. Meanwhile, the $J_{\text {nrdiff }}$ of SBS I-C at
TABLE 5: Rutting test results of asphalt mixtures.

\begin{tabular}{lccccc}
\hline Mixture types & AH-70 & AH-90 & SBS I-C & SBS I-D & HVG \\
\hline DS/times $\cdot \mathrm{mm}^{-1}$ & 868 & 597 & 4741 & 8395 & 10263 \\
\hline
\end{tabular}

$70^{\circ} \mathrm{C}$ was 1.18 times that at $64^{\circ} \mathrm{C}$, but the $J_{\mathrm{nr} 3.2}$ increased by 3.37 times, which was obviously unreasonable. It indicates that, for some modified asphalts, too small $J_{\mathrm{nr} 0.1}$ or too large $J_{\mathrm{nr} 3.2}$ will lead to the $J_{\text {nrdiff }}$ cannot be less than $75 \%$ of the specification, which cannot accurately reflect the stress sensitivity of asphalt. Meanwhile, it is noted that results of $J_{\text {nrslope }}$ and $J_{\mathrm{nr} 3.2}$ are consistent. The $J_{\text {nrslope }}$ of SBS I-D at $82^{\circ} \mathrm{C}$ is 4.47 times that at $76^{\circ} \mathrm{C}$, and the corresponding $\mathrm{V}_{\mathrm{nr} 3.2}$ is also expanded by 4.52 times. Similar rules are reflected in different temperatures and different asphalts, which indicates that $J_{\text {nrslop }}$ can well describe the stress sensitivity of modified asphalt. As can be seen from Figure 4(f), the stress sensitivity of modified asphalt becomes more significant with the increase of temperature. At $88^{\circ} \mathrm{C}$, the stress sensitivity of modified asphalt approaches or exceeds that of matrix asphalt.

4.3. Comparison of the Test Results. Rutting test results of five asphalt mixtures selected in this paper are shown in Table 5. According to the rutting test results of asphalt mixture at $60^{\circ} \mathrm{C}$ and MSCR and DSR test results at $64^{\circ} \mathrm{C}$, the rutting performance of the five types asphalts were ranked. It can be seen from Table 6 that the ranking results of $J_{\mathrm{nr} 0.1}, J_{\mathrm{nr} 3.2}$, and $J_{\text {nrslope }}$ were consistent with the rutting test results, but $J_{\text {nrdiff }} G^{*} / \sin \delta$, is different from them. The latter two indexes can not characterize the rutting resistance of modified asphalt. Figure 5 shows that $J_{\mathrm{nr} 0.1}, J_{\mathrm{nr} 3.2}$, and $J_{\text {nrslope }}$ are significantly correlated with rutting test results of asphalt mixture at the 5\% level, and their correlation coefficients $R$ are all greater than the critical value of 0.8783 at the $5 \%$ level. As predicted above, $J_{\text {nrdiff }}$ is not correlated with rutting test results. It is worth noting that $G^{*} / \sin \delta$ has a good linear relationship with rutting test results 
TABLE 6: Ranking of rutting resistance based on rutting test results at $60^{\circ} \mathrm{C}$; MSCR and DSR results at $64^{\circ} \mathrm{C}$.

\begin{tabular}{|c|c|c|c|c|c|c|}
\hline Type of binders & DS & $J_{\mathrm{nr} 0.1}$ & $J_{\mathrm{nr} 3.2}$ & $J_{\text {nrslope }}$ & $J_{\text {nrdiff }}$ & $G^{*} / \sin \delta$ after RTFOT \\
\hline HVG & 1 & 1 & 1 & 1 & 1 & 2 \\
\hline SBS I-D & 2 & 2 & $\mathrm{~s}$ & 2 & 4 & 1 \\
\hline SBS I-C & 3 & 3 & 3 & 3 & 5 & 3 \\
\hline AH-70 & 4 & 4 & 4 & 4 & 2 & 4 \\
\hline $\mathrm{AH}-90$ & 5 & 5 & 5 & 5 & 3 & 5 \\
\hline
\end{tabular}

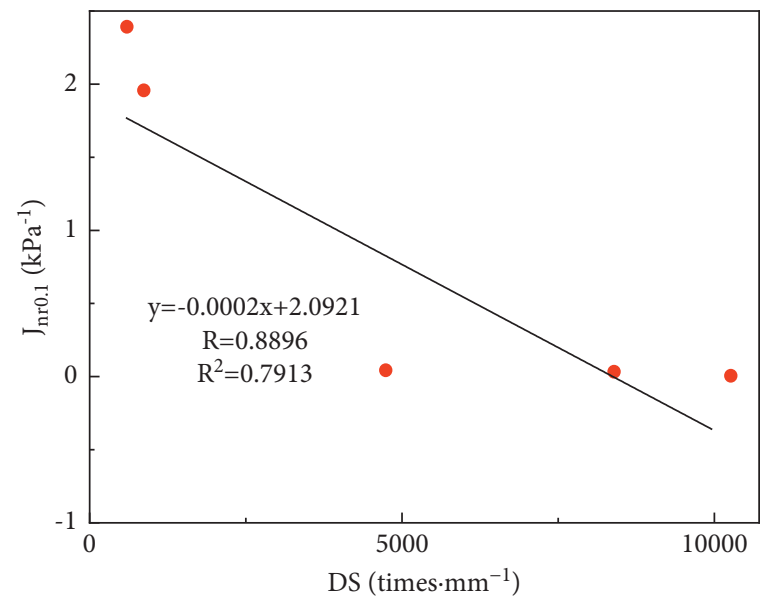

(a)

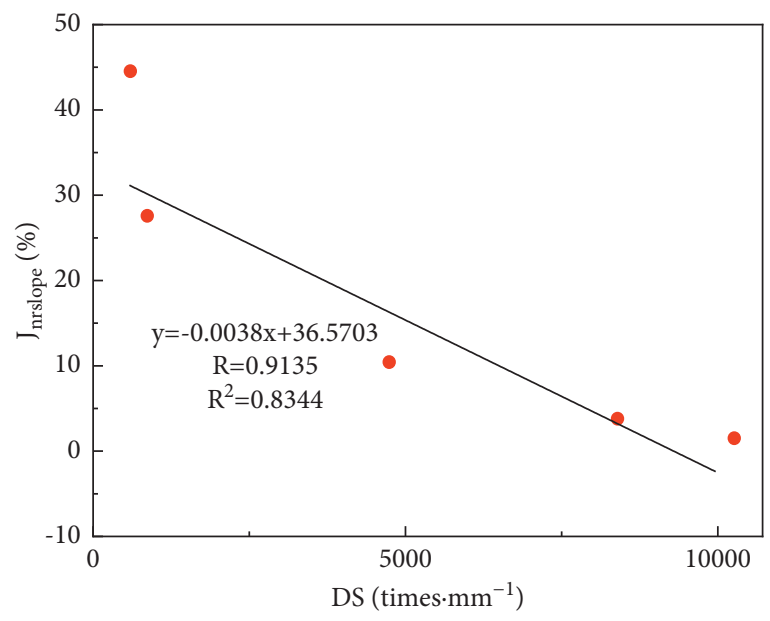

(c)

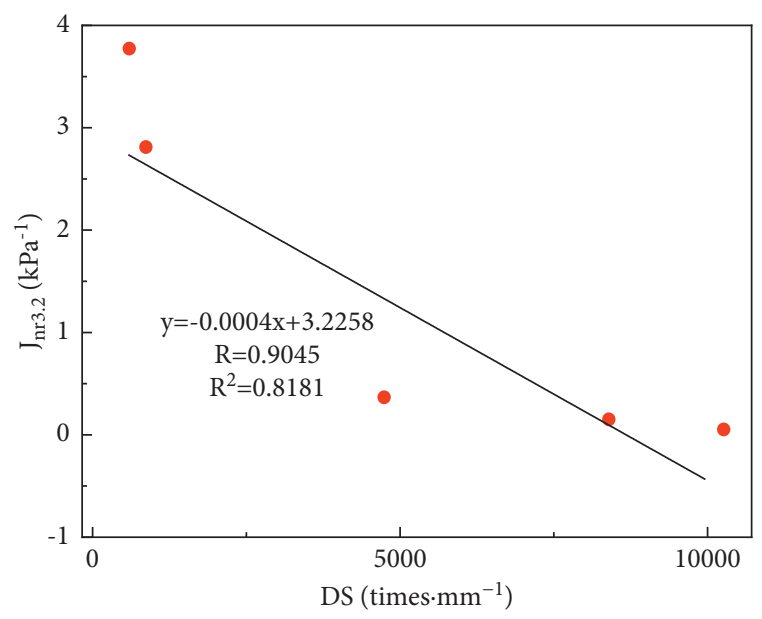

(b)

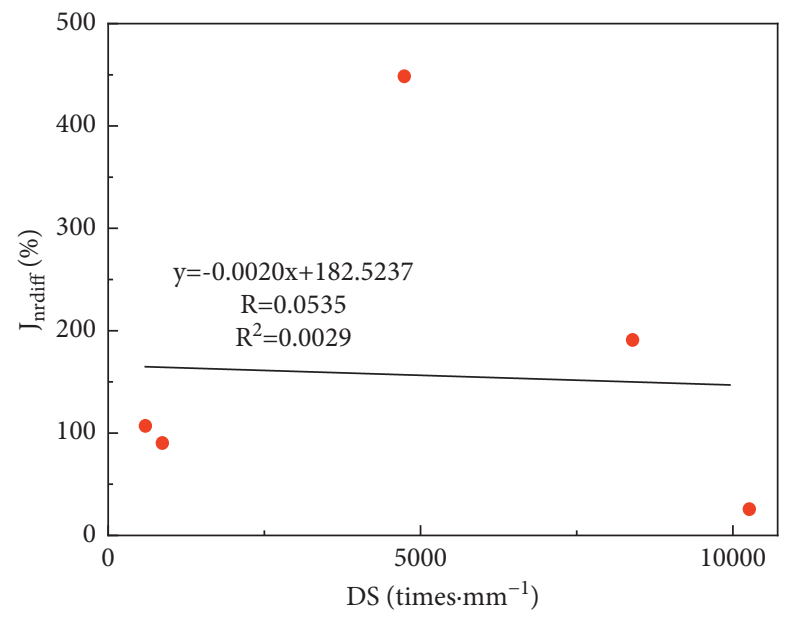

(d)

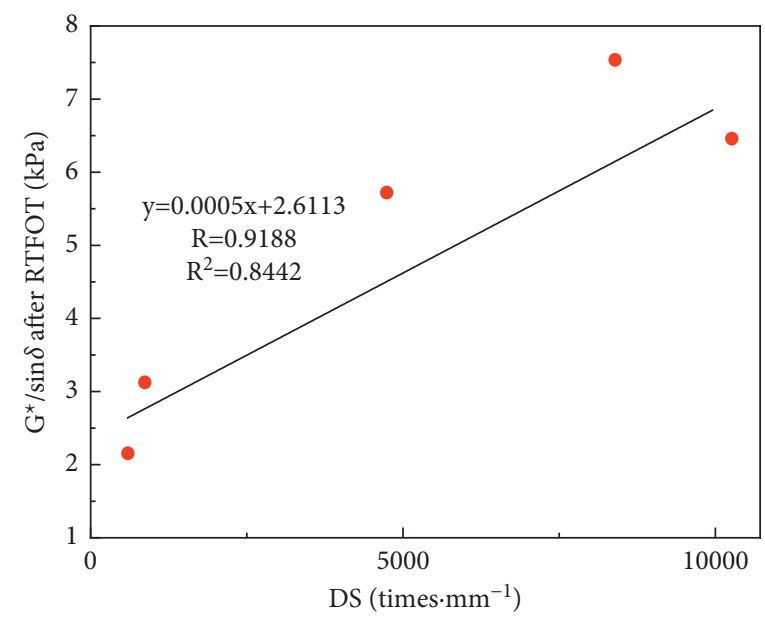

(e)

FIGURE 5: Correlations of DS and (a) $J_{\text {nr0.1. }}$ (b) $J_{\text {nr3.2. }}$ (c) $J_{\text {nrslope }}$ (d) $J_{\text {nrdiff. }}$ (e) $G^{*} / \sin \delta$ after RTFOT at $64^{\circ} \mathrm{C}$. 


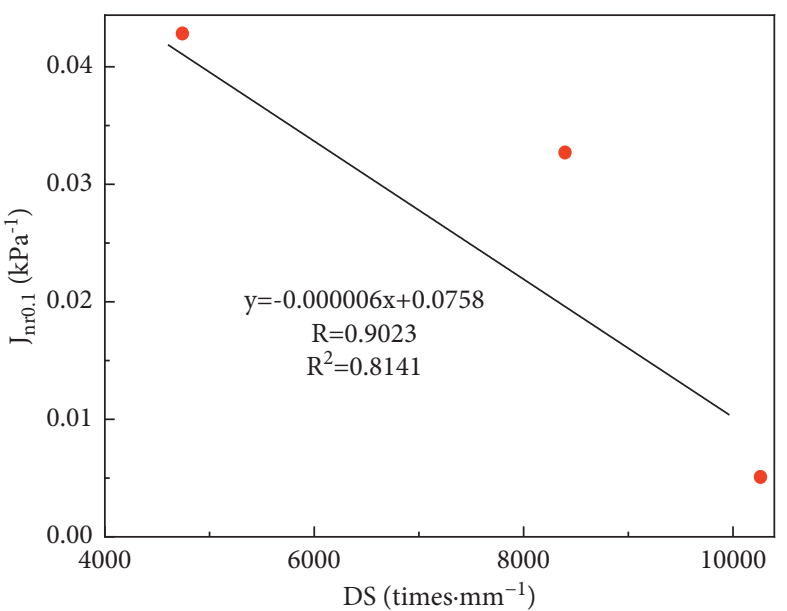

(a)

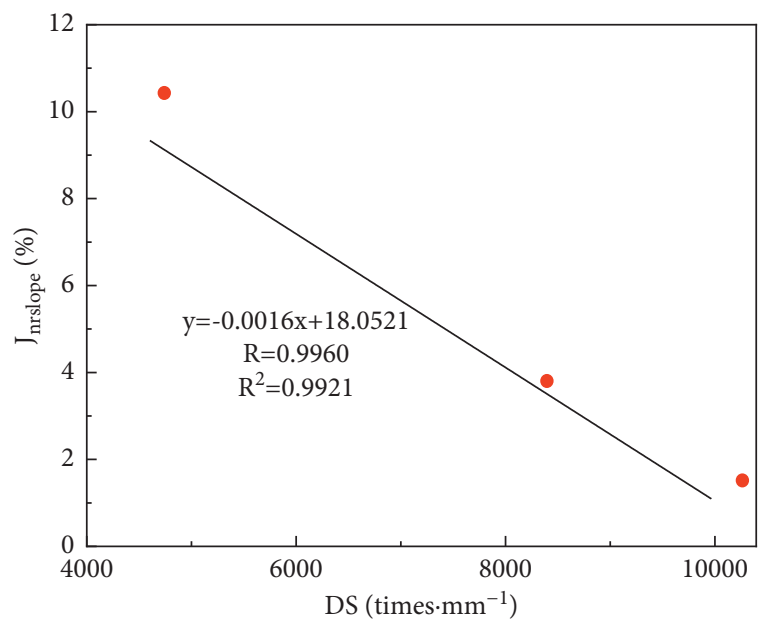

(c)

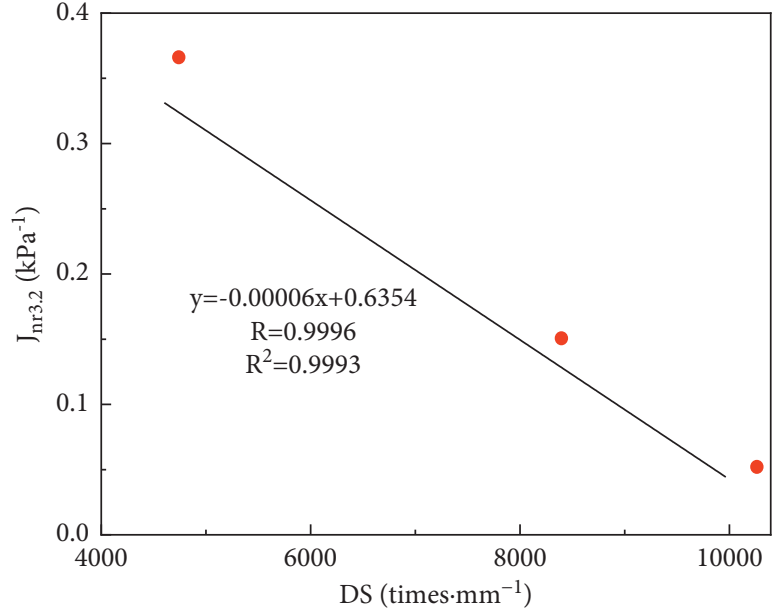

(b)

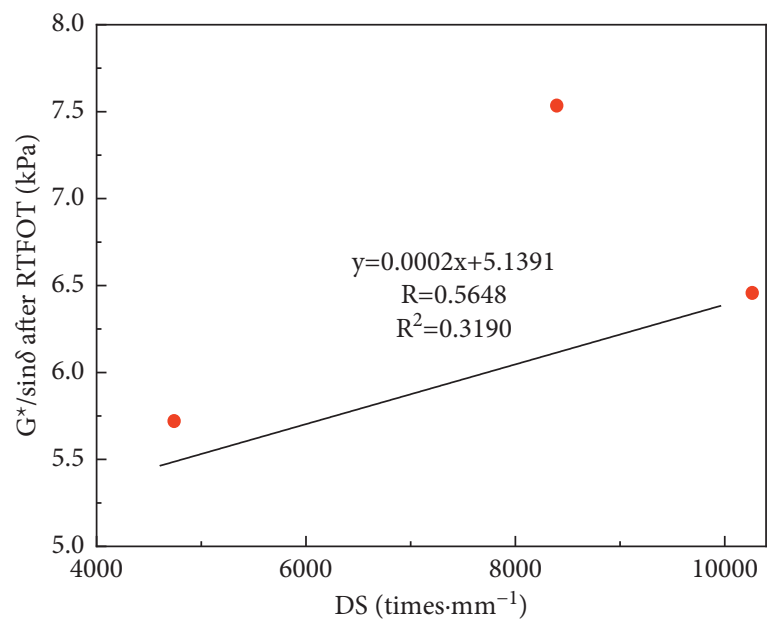

(d)

FIGURE 6: Correlations of DS and (a) $J_{\text {nro.1 }}$ of modified asphalt. (b) $J_{\text {nr3.2 }}$ of modified asphalt. (c) $J_{\text {nrslope }}$ of modified asphalt. (d) $G^{*} /$ sin $\delta$ after RTFOT of modified asphalt.

after RTFO aging, which is contradictory to the conclusion of other researchers that DSR is not applicable to modified asphalt [8-10]. Therefore, the experimental results of modified asphalt need further correlation analysis.

Figure 6 shows the linear correlation between test results of modified asphalt binder and rutting results of mixture at $64^{\circ} \mathrm{C}$. It can be seen that, at $5 \%$ level, $J_{\mathrm{nr} 3.2}$ still has significant correlation with rutting test results, and its correlation coefficient $R$ is greater than the critical correlation coefficient 0.9969 . At the $10 \%$ level, $J_{\text {nrslope }}$ is significantly correlated with rutting test results, while $J_{\text {nro.1 }}$ and $G^{*} / \sin \delta$ are not significantly correlated with rutting test results. This indicates that $J_{\text {nr3.2 }}$ and $J_{\text {nrslope }}$ can well characterize the rutting resistance of asphalt, while $J_{\text {nr0.1 }}$ and $G^{*} / \sin \delta$ are not suitable for characterizing the rutting resistance of modified asphalt.

\section{Conclusion}

In this study, the permanent deformation resistance of five different asphalts was evaluated. DSR and MSCR tests were carried out to obtain the irreversible creep compliance and strain recovery rate of the material. The rutting test of densegraded asphalt mixture with the same binder composition was carried out to determine its antirutting ability. The key findings are summarized as follows:

(1) Modified asphalt has better rutting resistance than matrix asphalt and can maintain good permanent deformation resistance at higher temperature, but the stress sensitivity of modified asphalt increases with the temperature.

(2) The $J_{\text {nr3.2 }}$ obtained by MSCR test is significantly correlated with the rutting test result DS of asphalt mixture, indicating that $J_{\mathrm{nr} 3.2}$ can well correlate the permanent deformation resistance of binder with the rutting resistance of asphalt mixture and is an important index to evaluate the rutting resistance effect of binder in asphalt mixture.

(3) $J_{\text {nrdiff }}$ is no longer suitable as an evaluation index of asphalt stress sensitivity due to too small $J_{\text {nr0.1 }}$ or too large $J_{\text {nr3.2 }}$ in some modified asphalt; $J_{\text {nrslope }}$ can better characterize the stress sensitivity of asphalt, 
and linear correlation analysis results show that it has significant correlation with the results of rutting test.

(4) The negative recovery rate $R$ is usually found in the matrix asphalt with weak rutting resistance, and this phenomenon is more obvious under the test conditions of high temperature and high stress. It is suggested that lower temperature and lower stress level should be used to evaluate the deformation recovery performance of matrix asphalt.

\section{Prospect}

This study only compared the rutting performance of five asphalt binder and dense-graded asphalt mixture prepared from the same binder. It is necessary to study the relationship between discontinuous gradation and open gradation asphalt mixture and asphalt binder performance in the future. Additionally, it is necessary to study the relationship between rutting and high temperature rutting resistance of asphalt in future.

\section{Data Availability}

The data used to support the findings of this study are included within the article.

\section{Conflicts of Interest}

The author declares no conflicts of interest.

\section{Acknowledgments}

This research was supported by the Basic Scientific Research of Central Institute (2020-9049).

\section{References}

[1] M. D. I. Domingos and A. L. Faxina, "Susceptibility of asphalt binders to rutting: literature review," Journal of Materials in Civil Engineering, vol. 28, no. 2, Article ID 04015134, 2016.

[2] J. Zhang, C. Zhu, X. Li, J. Pei, and J. Chen, "Characterizing the three-stage rutting behavior of asphalt pavement with semirigid base by using UMAT in ABAQUS," Construction and Building Materials, vol. 140, pp. 496-507, 2017.

[3] Y. Du, J. Chen, Z. Han, and W. Liu, "A review on solutions for improving rutting resistance of asphalt pavement and test methods," Construction and Building Materials, vol. 168, pp. 893-905, 2018.

[4] M. N. Partl, H. U. Bahia, F. Canestrari et al., Advances in Interlaboratory Testing and Evaluation of Bituminous Materials: State-Of-The-Art Report of the RILEM Technical Committee 206-ATB, pp. 18-83, Springer Science \& Business Media, Heidelberg, Germany, 2012.

[5] L. F. Walubita, E. Mahmoud, L. Fuentes et al., "Correlating the asphalt-binder high-temperature properties (DSR) to HMA permanent deformation (RLPD) and field rutting: a laboratory-field study," Construction and Building Materials, vol. 262, p. 120761, 2020.

[6] J. Petersen, R. Robertson, J. Branthaver et al., Binder Characterization and Evaluation: Volume 1. Rep. No. SHRP-A-367, Strategic Highway Research Program, National Research Council, Washington, DC, USA, 1994.
[7] AASHTO, Standard Test Method for Determining the Rheological Properties of Asphalt Binder Using a Dynamic Shear Rheometer (DSR), AASHTO T, Washington, DC, USA, 2012.

[8] H. Bahia, D. Hanson, M. Zeng, H. Zhai, M. Khatri, and R. Anderson, NCHRP Report 459: Characterization of Modified Asphalt Binders in Superpave Mix Design, Transportation Research Board of the National Academies, Washington, DC, USA, 2001.

[9] H. U. Bahia, H. Zhai, M. Zeng, Y. Hu, and P. Turner, "Development of binder specification parameters based on characterization of damage behavior (with discussion)," Journal of the Association of Asphalt Paving Technologists, vol. 70, 2001.

[10] R. Dongré and J. D’Angelo, “Refinement of Superpave hightemperature binder specification based on pavement performance in the accelerated loading facility," Transportation Research Record, vol. 1829, no. 1, pp. 39-46, 2003.

[11] J. A. D’Angelo, "The relationship of the MSCR test to rutting," Road Materials and Pavement Design, vol. 10, no. sup1, pp. 61-80, 2009.

[12] Z. I. Qasim, A. H. Abed, and K. A. Almomen, "Evaluation of mixing and compaction Temperatures (MCT) for modified asphalt binders using zero shear viscosity and Cross-Williamson model," Case Studies in Construction Materials, vol. 11, Article ID e00302, 2019.

[13] A. Shenoy, "Refinement of the Superpave specification parameter for performance grading of asphalt," Journal of Transportation Engineering, vol. 127, no. 5, pp. 357-362, 2001.

[14] K. Yan, L. You, and D. Wang, "High-temperature performance of polymer-modified asphalt mixes: preliminary evaluation of the usefulness of standard technical index in polymer-modified asphalt," Polymers, vol. 11, no. 9, p. 1404, 2019.

[15] AASHTO, MP19-10, American Association of State Highway and Transportation Officials, Washington, DC, USA, 2014.

[16] H. Liu, W. Zeiada, G. G. Al-Khateeb, A. Shanableh, and M. Samarai, "Use of the multiple stress creep recovery (MSCR) test to characterize the rutting potential of asphalt binders: a literature review," Construction and Building Materials, vol. 269, p. 121320, 2021.

[17] K. Al-Adham, M. A. Dalhat, and H. I. Al-Abdul Wahhab, "Strain recovery rate and absolute per cent recovery of polymer-modified asphalt binders," International Journal of Pavement Engineering, vol. 21, no. 7, pp. 919-929, 2020.

[18] N. Saboo and P. Kumar, "Analysis of different test methods for quantifying rutting susceptibility of asphalt binders," Journal of Materials in Civil Engineering, vol. 28, no. 7, Article ID 04016024, 2016.

[19] F. Zhou, H. Li, P. Chen, and T. Scullion, Laboratory Evaluation of Asphalt Binder Rutting, Fracture, and Adhesion Tests, Texas A\&M Transportation Institute, Austin, TX, US, 2014.

[20] China, Standard Test Methods of Asphalt and Asphalt Mixtures for Highway Engineering, China Communication Press, Beijing, China, 2011.

[21] China, Technical Specifications for Construction of Highway Asphalt Pavements JTG F40-2004, Ministry of Transport of the People's Republic of China, Beijing, China, 2004.

[22] AASHTO, Standard Method of Test for Multiple Stress Creep Recovery (MSCR) Test of Asphalt Binder Using a Dynamic Shear Rheometer (DSR), AASHTO T, Washington, DC, USA, 2014.

[23] J. B. S. Bastos, L. F. A. L. Babadopulos, and J. B. Soares, "Relationship between multiple stress creep recovery (MSCR) binder test results and asphalt concrete rutting resistance in 
Brazilian roadways," Construction and Building Materials, vol. 145, pp. 20-27, 2017.

[24] M. Gaspar, B. Nogueira, K. Vasconcelos, L. Leite, and L. Bernucci, "Effect of different creep and recovery times on the MSCR test for highly modified asphalt binder," Journal of Testing and Evaluation, vol. 49, 2019.

[25] O.-V. Laukkanen, H. Soenen, T. Pellinen, S. Heyrman, and G. Lemoine, "Creep-recovery behavior of bituminous binders and its relation to asphalt mixture rutting," Materials and Structures, vol. 48, no. 12, pp. 4039-4053, 2015.

[26] J. Stempihar, A. Gundla, and B. S. Underwood, "Interpreting stress sensitivity in the multiple stress creep and recovery test," Journal of Materials in Civil Engineering, vol. 30, no. 2, Article ID 04017283, 2018.

[27] M. Jafari, A. Babazadeh, and S. Aflaki, "Effects of stress levels on creep and recovery behavior of modified asphalt binders with the same continuous performance grades," Transportation Research Record: Journal of the Transportation Research Board, vol. 2505, no. 1, pp. 15-23, 2015.

[28] B. Singh, N. Saboo, and P. Kumar, "Effect of short-term aging on creep and recovery response of asphalt binders," Journal of Transportation Engineering, Part B: Pavements, vol. 143, no. 4, Article ID 04017017, 2017. 